\title{
Redesign and Comprehensive Renovation of the Walker Management Library
}

\author{
HILARY A. CRAIGLOW \\ Vanderbilt University, Nashville, TN \\ hilary.craiglow@vanderbilt.edu
}

\begin{abstract}
This article presents an overview of the redesign and comprehensive renovation of the Walker Management Library. From ideation to completion, the library is now a highly functional space for quiet study and collaboration and serves multiple purposes for the Owen Graduate School of Management, Vanderbilt University. The article describes purpose, process, and final results of the renovation project.
\end{abstract}

Keywords renovation, redesign, remodel, construction, quiet study, team room, collaborative space, lighting, furniture, finishes, architects

\section{Background}

The Walker Management Library is a 15,000-square-foot facility embedded in the Owen Graduate School of Management at Vanderbilt University. Named in honor of Thomas and Anne Marie Walker, the library is original to the 1982 construction of Management Hall. Thomas "Tommy" Walker was a 1947 graduate of Vanderbilt and a successful investment banker, first with Equitable Securities and later Goldman Sachs. He was a member of the Vanderbilt Board of Trustees, and one of his many generous donations to the university provided library space and materials in support of the programs of the Owen Graduate School of Management.

Housing all of Vanderbilt's graduate-level business programming, Management Hall buzzes with activity. Degree and non-degree programs happen year-round, each day of the week. The library occupies two floors on the south side of the three-story building and, administratively, reports to the university library system. The library's primary constituency is faculty and students who are engaged in the work of the Owen School. Currently, there are eight library positions, including a director, four librarians, and three library service providers, plus several student positions. Custom library programing is developed for each of the degree and non-degree programs, as well as the undergraduate business minor housed elsewhere on campus. Alumni engagement, including services and resources, is an important part of the library's mission.

In July of 2013, M. Eric Johnson became dean of the Owen Graduate School of Management. Dean Johnson returned to Owen after almost 15 years at another institution. He brought back his infectious positivity to a physical building and library that hadn't changed dramatically since the time he was a professor in the 1990s. Soon after starting his tenure as dean, he said: "Imagine your ideal academic business library; what that would look like?" In late 2015, we embarked on a process that resulted in a comprehensive library renovation, completed during the summer of 2017.

\section{Vision}

Management Library resources and services continually evolve to keep up with demands of business education in the $21^{\text {st }}$ century. The library space in 2015 did not match the needs of teaching, learning, 
Ticker: The Academic Business Librarianship Review, 4:2 (2020)

http://doi.org/10.3998/ticker.16481003.0004.206

(C)2020 Hilary Craiglow

and research nor match the needs of the life of an active graduate business school. Over the years the library had moderate enhancements, e.g. addition of team rooms, new carpeting, and updated furniture. However, in a discipline that does not rely heavily on monographs, in a building bursting at the seams, book stacks stand out. Another area of obvious concern is the Owen School's packed calendar. Programing is continuous, running around the calendar and around the clock. The library space needed to be more accessible, work more effectively, and for more people.

\section{Teamwork}

To detail, prioritize, and optimize a renovation of the library space, we engaged with several stakeholders and experts. Along with the library director, the team included the Owen School's chief business officer ( $\mathrm{CBO}$ ), who happened to be an MBA alum and former student government vice president; our associate dean for MBA programs; two MBA students; and, when available, the dean. Also fully engaged with the process were Vanderbilt's campus planning experts, local architects, and designers.

\section{Planning \& Process}

For almost a year, the group underwent an ideation process about what a $21^{\text {st }}$ century business library, at Owen, should be and what it would look like. In addition to the members of the team, input was gathered through student focus groups, educational technologists, faculty, and the yearly student satisfaction surveys. Once the overall goals and priorities were confirmed, a first set of drawings and feasibility work was conducted. The dean and CBO worked on funding. There were multiple iterations of drawings, construction and supplier bids, final drawings, and then a construction plan. When all the pieces came together, a final construction plan was put in place. With an effort to displace as few programs and events as possible, construction was planned around the core MBA academic calendar.

Although there was almost a year of ideation, once there was a clear signal that the project would be funded, the process moved very swiftly. In all, the process from ideation to completion was only a year and a half.

\section{Goals}

The ideation process gave us a clear picture of the project priorities. The primary project goals were:

\section{To improve the quantity and quality of quiet and individual study}

The quiet study areas were well utilized by students, but the configuration and furniture did not optimize the space. Today, where media is $24 / 7$, screens are ever present, and we are bombarded by sound, images, busy schedules, and a vibrant active building, spaces that are quiet and thoughtful are necessary. The library is a needed refuge where people can go for real, deep thought. For the hard work that our students undertake, these spaces are needed now more than ever.

\section{To improve the quantity and quality of collaborative team spaces}

With most Owen courses including a team project and the Owen school focused on collaborative approaches to real-world business problems, spaces for teams to meet are imperative. The team rooms were small and dark, and noise transferred between the few available rooms. 
Ticker: The Academic Business Librarianship Review, 4:2 (2020)

http://doi.org/10.3998/ticker.16481003.0004.206

(C)2020 Hilary Craiglow

\section{To improve the quantity and consistency of team room technology}

Technology in each of the team rooms was inconsistent and unreliable. Never knowing what condition or what would be available was a constant source of frustration for users. The yearly student satisfaction surveys consistently placed team rooms and team room technology as one of the least satisfying aspects of the student experience.

\section{To provide space to gather groups of five to forty}

Management Hall includes conference rooms and classrooms and a flexible lobby, for school activities. Nowhere, however, was there space for intimate exchange of information or space where students could gather in informal group conversation with one of our many distinguished alumni or invited business leaders.

\section{To increase the hours that study and collaborative space is available for use}

Gone were the old turnstiles. Yet, to secure all the books and other assets, the doors to the library were locked when staff were not present. The work of the school exceeded realistic library staffing models. Creating a way to secure library assets, computers, books, and equipment for loan, while allowing as much access to collaborative and quiet study spaces as possible, was important.

\section{To improve the air quality, temperature control, and airflow}

HVAC is a regular concern within Management Hall. The library was either hot and stuffy or freezing cold. Heating, cooling, and airflow were never fully adjusted to meet the needs of the team rooms that were added over time. The current system could not be modified to fix the airflow and temperature problems.

\section{To make library staff and library information consultations more accessible}

In an attempt to make information access seamless and easy, library work has been largely kept invisible. The side effect is inaccessible, unapproachable and often misunderstood library work. Staff offices behind closed corridors gave unnecessary mystery and physical barriers to the library's most valuable asset: our staff of library professionals and information consultants.

\section{Construction}

Preparations began during spring break 2017. Books were moved to the off-site storage facility, and bound periodicals that were owned in secure electronic archives were recycled. The Management Library temporarily closed May 5, 2017, with a planned reopening August 9, 2017. Directly following the last exam for the academic year, demolition began. During construction, librarian services and collections were still available to faculty, although there were no check-out services. Some library staff were located elsewhere in the building and some deployed to other campus libraries. The library director stayed close to construction activities and communicated regularly and broadly about the progress. Work was done around the clock and was completed in just three months. Workers concentrated their efforts and worked triple shifts to meet the short time frame. Normally a project of this size would have taken six months. The excellent coordination, professionalism, and hard work of the contractors meant that the project stayed on track, and the library opened just a few days after MBA classes started in August 2017. 
Ticker: The Academic Business Librarianship Review, 4:2 (2020)

http://doi.org/10.3998/ticker.16481003.0004.206

(C)2020 Hilary Craiglow

\section{Outcomes}

The new Walker Management Library is a welcoming, comfortable space for individual quiet study and team collaboration, with accessible staff and premium resources. It is a gorgeous and highly functional space that is the jewel of Management Hall. There is a wide variety of study configurations, one to suit everybody. Collaborative team rooms are big, bright, and have consistent technology from room to room. All seating is accessible to electricity for ease in plugging in student electronics and charging mobile devices. A fireplace is the focal point of the main first floor reading room. Study and collaborative spaces are available at any time. Library resources, services, and staff are accessible and visible.

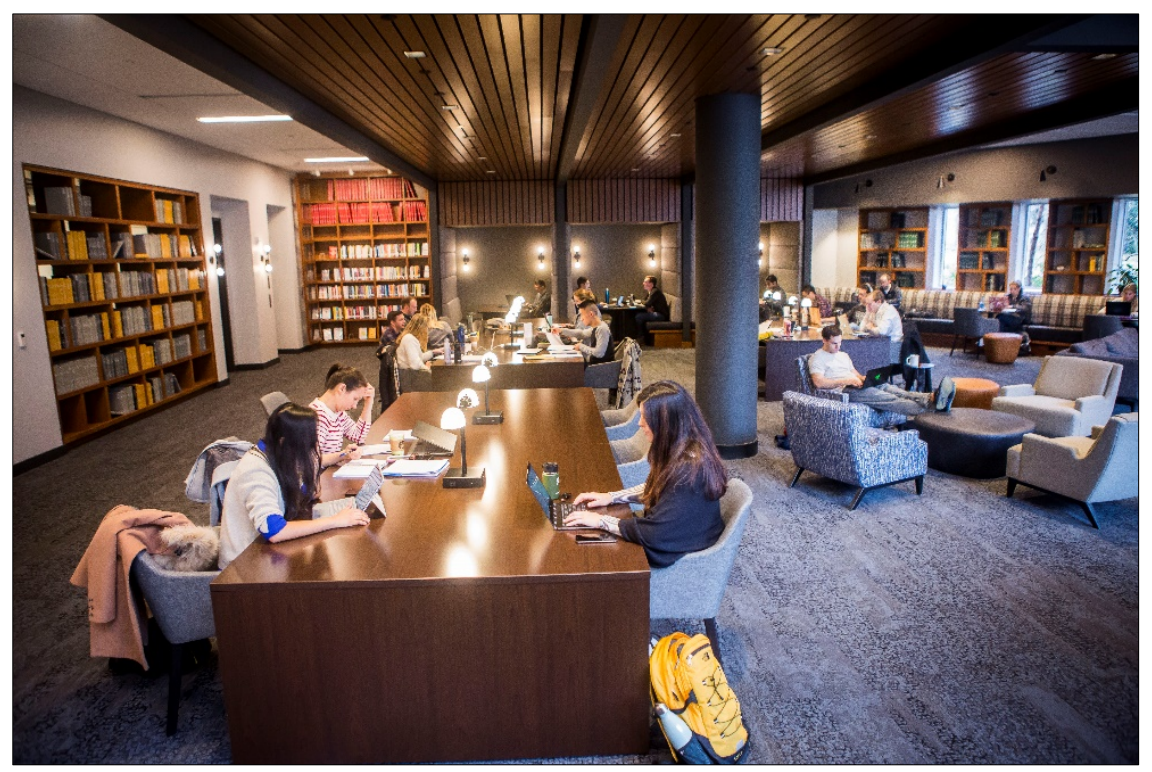

Image 1: New first floor reading room

\section{Quiet Study}

In the main first floor reading room, there is a variety of spaces for individual quiet study: traditional carrels, booths, couches, high backed chairs with ottomans, long tables, stand up desks, and reading nooks. All seating is accessible to electricity for ease in plugging in student electronics and charging mobile devices. The variety of seating and study configurations were largely based on survey input from Owen students.

\section{Sound}

The entire library benefits from sound mitigation through design, architecture, and finishes. From the plush carpet, ceiling panels, soft seating, and thoughtful design, the quiet study areas create space for deep thought and focus. A sound masking system was installed through the entire library. Engineered to match voice frequency, it helps keep talking distractions to a minimum. Both floors of the library were designed with sound absorbing finishes, and sound mitigation continues with lowered ceilings and narrower corridors. 


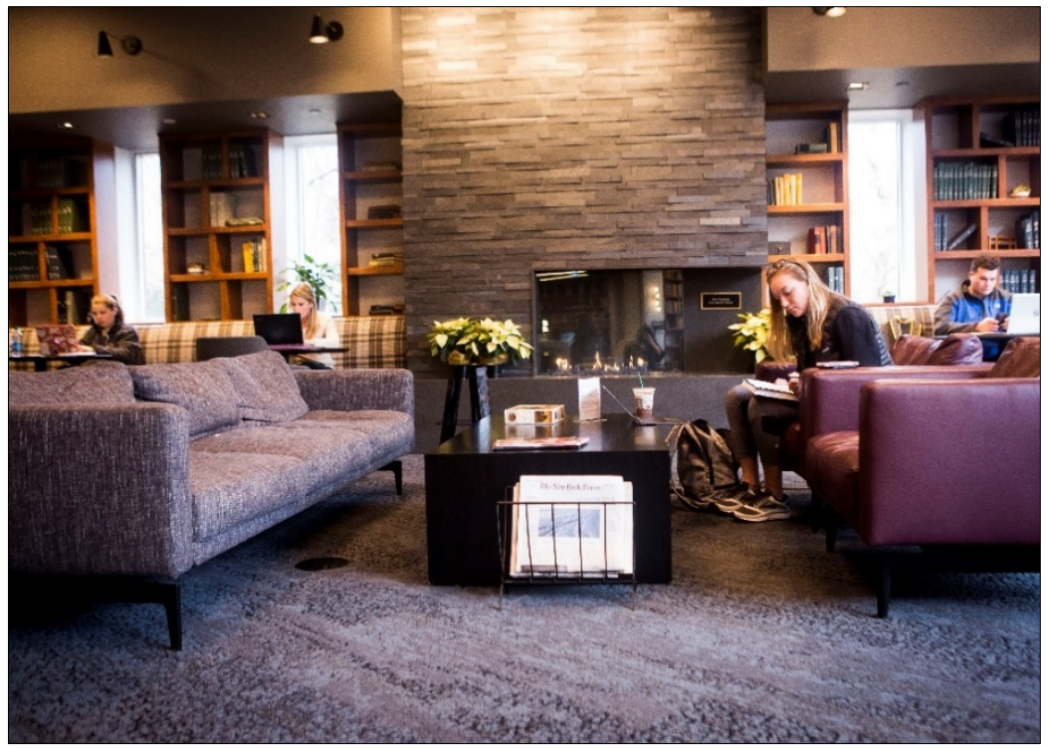

Image 2: Fireplace

\section{Flexible Space}

The central focal point of the first floor reading room is a natural gas fireplace. Most of the time, the fireplace provides ambiance for deep contemplative thought. On special occasions, the dean, in consort with the library, utilizes the space to engage with business leaders in a personal setting. This is a space like no other at Owen. The furniture around the fireplace can be converted from individual study to a reverent gathering area for a group of four to forty people.

\section{Collaborative Spaces}

We increased the quality, size, and number of team rooms. The twenty-one team rooms have less sound transfer and improved, consistent technology. Most of the rooms seat six; one seats eight, and there is a second twelve-person conference room. The team rooms are all off one corridor, to help with sound transfer to the rest of the library. The rooms have glass walls and frosted windows that provide natural light to improve the quality of the room experience.

\section{Team Room Technology}

We chose a new all-in-one system from Crestron for presenting and video conferencing. The rooms have 55 " screens and use AirMedia for wireless presenting. The technology is flexible; at some point in the future it can communicate with a room reservation system. All rooms have cameras, glass white boards, and flexible seating that can be rearranged. All electric wires are hidden in furniture legs and behind walls.

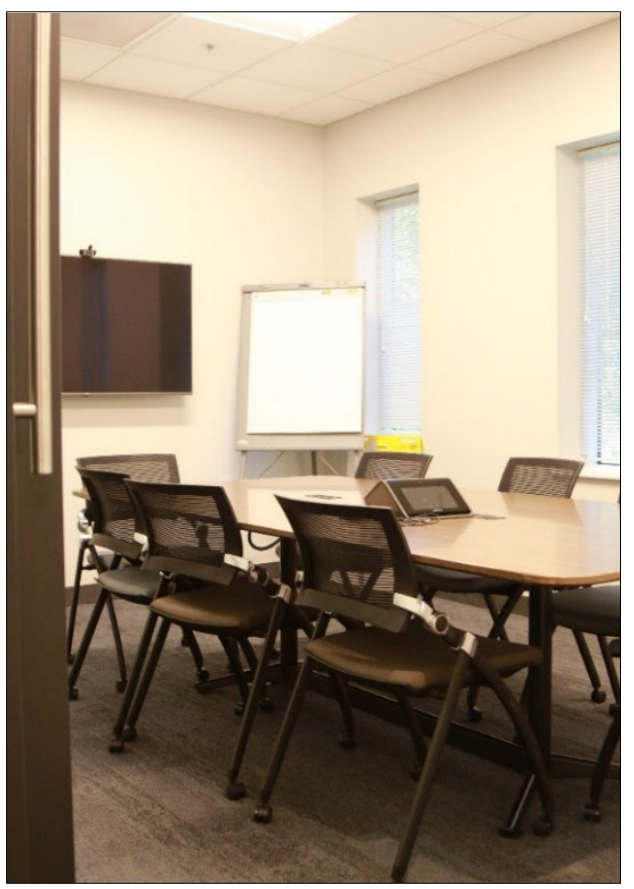

Image 3: Sample team room 
Ticker: The Academic Business Librarianship Review, 4:2 (2020)

http://doi.org/10.3998/ticker.16481003.0004.206

(C)2020 Hilary Craiglow

\section{Temperature and Air Quality}

The entire space benefits from a new 10-ton air handler that was placed on the roof of Management Hall. All-new ducts, vents, sensors, and thermostats have been installed through the entire space. Each team room, conference room, office and reading room zone can be individually controlled, allowing for comfortable air flow and temperature. The new system provides relief to the rest of Management Hall's older HVAC system.

\section{Availability}

The first floor and second floor study spaces, as well as all the team rooms, print center, and the library conference room are available to the Owen community $24 / 7$. There are 12 security cameras placed throughout the library designed to help keep students safe when studying late at night. The library is available to the Vanderbilt community whenever Management Hall is open.

\section{Print Center}

The renovation includes a 24-hour copy and collating room for students. It has two multifunction machines and ample paper supplies, three-hole punches, staplers, paper cutter, etc.

\section{Restrooms/Changing Rooms}

The second floor restrooms are all-gender and large enough to function as changing rooms so that students can go from class to interview. Full length mirrors, hooks for clothing, and sinks designed with a small vanity area help students look their best to make a great first impression.

\section{Conference Room}

The first floor library conference room is a beautiful board room, with extra-large video screen, 360degree video conferencing camera, and a sound system in the ceiling. It includes a glass feature wall that provides a rear view of books shelved on the other side of the wall.

\section{Service Area}

Valuable library assets, e.g., equipment for check-out, books, Bloomberg terminals, etc., staff offices, and books are consolidated into one part of the first floor. An overhead gate separates those assets from the rest of the study and collaborative spaces. When library services are unavailable, the gate is put down and locked, leaving much of the library space accessible.

\section{Library Staff Offices}

The glass-framed director's office and library service offices are visible from the main reading room and service area. Down an open corridor are librarian offices, easily accessible to visitors and conducive for information consultations. 


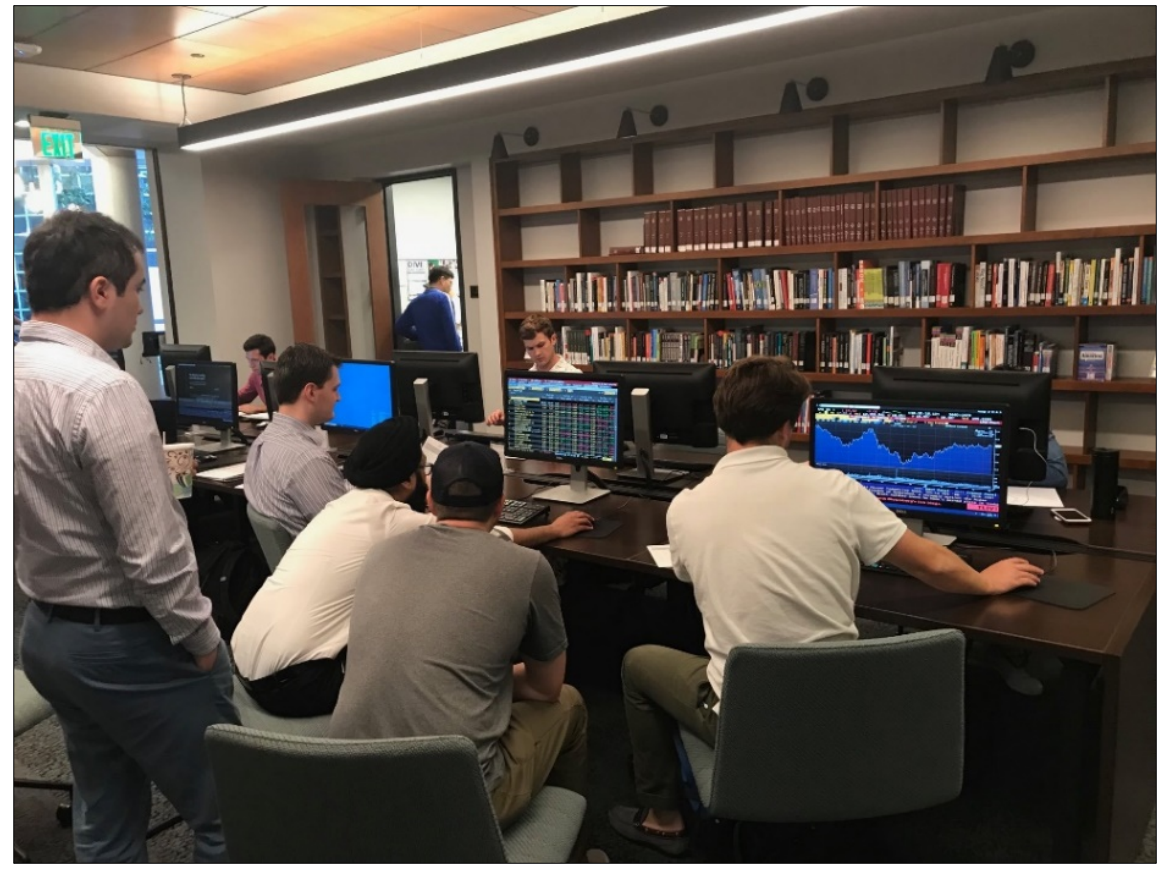

Image 4: Computer "lab" with view to print center Photo credit: Author-supplied photo

\section{Computer "Lab"}

The library includes a bank of 10 monitors connected to virtual machines, with installed data and software. With a rolling large format monitor, the area can also be used as a teaching lab.

\section{Print Materials}

The majority of the library book collection was moved off-site and can be retrieved upon request. The collection of books retained at the library are more practical in nature. There is also a browsing collection of new popular business books, business magazines, and newspapers. Current daily newspapers are put out by the fireplace.

\section{Light}

Management Hall is noted for is wall of windows, and this was optimized in the library redesign. Light flows through the entire space, including interior rooms, by employing glass walls, windows, and doors. Custom light fixtures and accent lights are seen throughout the space, including a statement piece in the stairwell. Lamps on long library tables increase access to plugs and USB ports.

\section{Finishes}

The finishes include a variety of fabrics, darker wood tones, granite, brass, and warm grey carpet and paint.

\section{Questions People Often Ask}

Total cost: $\$ 4.1$ million

Architects and designers: EOA Architects (Nashville, TN) Construction company: Burns Services, Inc. (Nashville, TN)

Yes, we allow food: covered drinks and snacks http://tinyurl.com/WMLreno 
Ticker: The Academic Business Librarianship Review, 4:2 (2020)

http://doi.org/10.3998/ticker.16481003.0004.206

(c)2020 Hilary Craiglow

\section{Notes on Funding}

A renovation like this, lasting and memorable, with positive impact for so many, cannot happen without the generosity of people dedicating their time and money to its creation. Fundraising for projects such as this are an important part of university life and operations. Although this work is generally left to professionals, the library can make a difference in making that work easier for development offices and deans. Providing alumni services has always been an important role of the Management Library. From licensing resources for alumni use, providing information consultation, and welcoming alumni back to campus, the library staff make alumni a priority. For this project, the library director and architects presented to important groups, such as the alumni board and board of visitors about the value and future of a business library in the $21^{\text {st }}$ century and what such a space could look like. Funding for this project comes with its own sadness. In the fall of 2016, we lost Tommy Walker. His bequest included financial support for the Walker Management Library. In addition, fundraising for the fireplace was inspired by a beloved and longtime Owen administrator who passed away too soon.

\section{Final Notes}

By many accounts, this project was very successful (recently winning an International Interior Design Award). It is a point of pride for the Owen Graduate School of Management and the libraries at Vanderbilt. The new library is beautiful to look at - but the real beauty is how functional it is. It is often full of people and heavily used for a variety of school purposes. Throughout the whole process, communicating with stakeholders, students, faculty, staff, administrators, and alumni was key. Gathering input and perspective and then keeping everyone informed of progress, purpose, and service helped make the renovation process successful. The attention to detail from ideation, drawing, design, and construction has paid off. The attentiveness to function should mean that the space continues to work well for the needs of the students and faculty for many years to come.

It is an honor to work in such a beautiful space built on the memory and generosity of those who believe in the mission and work of the Walker Management Library, the Owen Graduate School of Management, and Vanderbilt University. 